Pakistan Journal of Intensive Care Medicine

eISSN: 2789-2905; pISSN: 2789-2891

www.pjicm.com

https://doi.org/10.54112/pjicm.v2021i1.3

Pak. J. Inten. Care Med., volume 2021:3

Research Article

\title{
MORTALITY AND COVID-19: A SNAPSHOT OF A TERTIARY CARE FACILITY IN PAKISTAN
}

\section{*RANA MA ${ }^{1}$, QAYYUM MA ${ }^{2}$, HASHMI MS ${ }^{1}$, SAIF MMU ${ }^{3}$, MUNIR MF ${ }^{3}$, PERVAIZ $\mathbf{R}^{1}$, IQBAL $\mathbf{S}^{4}$, HAFEEZ MM}

\author{
${ }^{I}$ Department of Internal and Critical Care Medicine, Bahria International Hospital, Lahore, Pakistan \\ ${ }^{2}$ Department of Internal Medicine and Nephrology, Bahria International Hospital, Lahore, Pakistan \\ ${ }^{3}$ Department of Critical care Nursing and Education, Bahria International Hospital, Lahore, Pakistan \\ ${ }^{4}$ Department of Cardiac Imaging. Northwest Heart Centre, Wythenshawe Hospital, Southmoor Road, M23 9LT, \\ Manchester, UK \\ ${ }^{5}$ Institute of Molecular biology and Biotechnology, University of Lahore, Lahore, Pakistan \\ Corresponding author email: drasimrana@yahoo.com
}

Keywords
Acute coronary syndrome;
Biochemical markers;
COVID-19 Infection;
Comorbid conditions;
Mortality
Received $2^{\text {nd }}$ January 2021;
Revised $3^{\text {rd }}$ April 2021;
online $5^{\text {th }}$ April 2021

Keywords

Biochemical markers,

COVID-19 Infection;

Mortality

online $5^{\text {th }}$ April 2021

\begin{abstract}
Background: Since SARS CoV-2 infection began in China and has evolved into a pandemic, mortality associated with this illness has been under discussion and hypercoagulability, severe acute respiratory syndrome and septicemia with multiple organ insufficiency have been cursed as potential causes of death in cases infected with the novel coronavirus. We did a retrospective analysis of cases admitted to our highly dependent and intensive care unit, and we tried to identify the leading cause of death in our cases. Methods: This is a single center retrospective study carried out at The Bahria International Hospital, Lahore over a 3-month period (May $10^{\text {th }}$ to July $10^{\text {th }}$, 2020) in which we analyzed the clinical and biochemical profiles of the COVID-19 patients who died during this period. Results: A total of 108 patients were admitted during this period out of which 11 patients died. Seven of them were men and 4 women. The majority of them had sudden cardiac arrest due to acute coronary syndrome followed by multiorgan dysfunction syndrome and acute respiratory distress syndrome. Conclusion: Acute coronary syndrome due to hypercoagulability was the leading cause of death in our patients.
\end{abstract}

and their casualty rate was $1.36 \%$ (Ali et al., 2020; Siddique et al., 2020; Tu et al., 2020). The total number of COVID-19 patients to date are approximately 0.3 million with under 7000 deaths in total (Seah and Agrawal, 2020).

The virus belongs to a genus similar to the severe acute respiratory syndrome coronavirus (SARS-CoV) and Middle East Respiratory Syndrome (MERS$\mathrm{CoV}$ ) and was therefore named SRAS-CoV-2 by the International Committee on Virus Taxonomy on February 11, 2020. However, SARS-CoV-2 is more infectious than SARS-CoV and MERS-CoV, with more than 84,000 cases in China and more than 4,200,000 cases globally as of May 12, 2020, by Science and Systems Engineering Community at John Hopkins University (David et al., 2020). On February 11, 2020, the World Health Organization officially named the new coronavirus (COVID-19)

[Cite: Rana MA, Qayyum A, Hashmi M, Saif MMU, Munir MF, Pervaiz R, Iqbal S, HAFEEZ MM. (2021). Mortality and COVID-19: A snapshot of a tertiary care facility in Pakistan. Pak. J. Inten. Care Med., 2021: 3. https://doi.org/10.54112/pjicm.v2021i1.3]. 
illness. SARS-CoV-2 is susceptible to transmission in family groups or to outbreak in hospitals (Azkur et al., 2020; Nadeem et al., 2021; Zheng et al., 2020a). Most COVID-19 patients experience mild and moderate symptoms, but severe cases may include acute respiratory distress syndrome (ARDS), multiple organ dysfunction syndrome, and even death. The mortality rate associated with COVID-19 varies from $1.4 \%$ to $4.3 \%$ in several regions or hospitals (Aggarwal et al., 2020).

\section{Methodology}

The present retrospective study was carried out at the Bahria International Hospital, Lahore (31 ${ }^{\circ} 34^{\prime}$ 55.3620' $\mathrm{N}$ and $\left.74^{\circ} 19^{\prime} 45.7536^{\prime} \mathrm{E}\right)$ from 10 May to 10 July 2020. The study has been approved by the Institutional Review Board and Ethical committee. A total of $108(n=108)$ cases of COVID-19 infection confirmed by reverse transcription polymerase chain reaction (RT-PCR) were added to the study after obtaining informed written consent (Zhu et al., 2020a). In this study, we focus on reviewing and highlighting the clinical and biochemical features of our fatal cases. Clinical and laboratory test results, along with clinical management data, were obtained using medical record data collection forms. The data were reviewed by most experienced physicians of hospital. Information collected included demographics, medical history, underlying products, laboratory results and details of clinical management. Continuous variables were measured in percentages and the standard deviation (SD) was computed numbers and percentages $(\%)$. Deviation of body biochemistry from normal ranges also described for the analysis of patient laboratory results. For statistical analysis, SPSS (version 21.0) was used.

\section{Results}

In this study, one hundred and eight admitted cases were included between May 10 and July 10. Thirty patients were transferred to the ICU and eleven of the thirty patients died of severe COVID-19 infection. Analysis of biochemical variables and clinical status demonstrated that men with comorbidity are more likely to develop a critical stage. The mean age was 56.36 years (interquartile range 42 to 68 years). 7 $(63.63 \%)$ were men, while $4(36.36 \%)$ were women. The average time between clinical onset and presentation on the day of death in hospital was 7 days (IQR-1-15 days), as indicated in the table below. Men were in=7 (63.6 per cent) and women were $n=4$ ( 36.4 per cent). Comorbidities have been observed in all deaths. The most common comorbidity was COPD $n=5(45.5 \%)$, followed by hypertension $n=3(27.3 \%)$ and ischemic heart disease $\mathrm{n}=3(27.3 \%)$. Over this study period, 108 confirmed
COVID-19 cases resulted in death or discharge, resulting in a death rate of $10.18 \%$. The most common cause of death was Cardiac arrested 7 (63.6\%) followed by multi organ dysfunction syndrome $2(18.2 \%)$ followed by ARDS (acute respiratory distress syndrome) 2 (18.2\%) (Figure 2). ARDS, Secondary bacterial infection, especially after the administration of Tocilizumab, (Tocilizumab is a recombinant humanized anti-interleukin-6 receptor (IL-6R) monoclonal antibody which has a main use in the treatment of rheumatoid arthritis) (Nicola et al., 2020). Acute renal injury and acute liver injury were common during hospitalization and resulted in a number of ICU admissions. All patients were given mechanical ventilation, corticosteroid (Methyl Prednisolone $40 \mathrm{mg}$ BD intravenous) antibiotics, including azithromycin. Antibiotics were intensified in 4 cases amidst worsening septic shock. Interestingly 7 cases died suddenly after they had been weaned off from mechanical ventilation and were out of secondary septic shock on acceptable Oxygen supplementation (5-6 liters per minute via simple face masks maintaining their $\mathrm{SpO}_{2} 96$ to 97\%). All developed sudden bradycardia followed by asystole and did not respond to CPR. Cardiac MR was done in a few cases to differentiate the acute MI from Myocarditis as the cause of rise of Troponins and that showed acute ischemic injury to myocardium strengthening our impression of Acute Coronary Syndrome to be the reason of sudden cardiovascular collapse (Figure 1). 4 cases experienced severe septic shock and multi-organ failure, whereas 2 cases had refractory ARDS and could not be oxygenated. All patients were treated with tocilizumab because they met the criteria for Cytokine Release Syndrome (CRS) (Gietema et al., 2020; Lauretani et al., 2020). Analysis of the biochemical profile indicated that serum levels of ferritin, LDH and D-Dimers were higher among nonresidents $($ mean $=1,370.22)$.

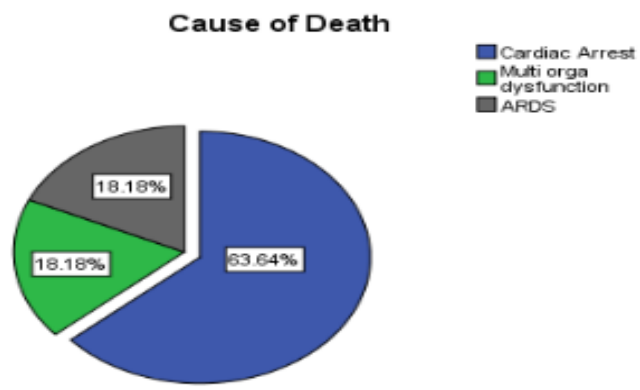

Figure 2. Death cause percentage

[Cite: Rana MA, Qayyum A, Hashmi M, Saif MMU, Munir MF, Pervaiz R, Iqbal S, HAFEEZ MM. (2021). Mortality and COVID-19: A snapshot of a tertiary care facility in Pakistan. Pak. J. Inten. Care Med., $2021: 3$. https://doi.org/10.54112/pjicm.v2021i1.3]. 


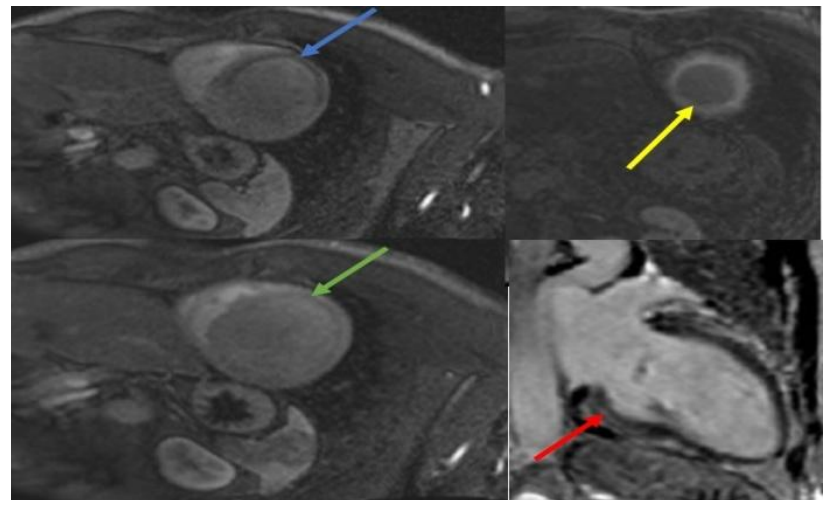

Figure 1: Cardiac Magnetic Resonance Images (CMR) - Reversible ischemia in anterior, anteroseptal and anterolateral wall segments (blue arrow) in a patient having LAD disease with corresponding rest image (green arrow). Apical infarct (yellow arrow) in another patient and myopericarditis (red arrow) in different patient on late gadolinium images

Table 1. Characteristics and laboratory results of included fatal cases of COVID-19

\begin{tabular}{|c|c|c|}
\hline & \multirow{3}{*}{$\begin{array}{l}\text { Mean (max-min) } \\
56.36(42-68)\end{array}$} & $\mathbf{N}(\%)$ \\
\hline & & \\
\hline \multicolumn{2}{|l|}{ Sex } & \\
\hline Male & & $7(63.6 \%)$ \\
\hline Female & & $4(36.4 \%)$ \\
\hline Number of days & $7(1-15)$ & \\
\hline \multicolumn{3}{|l|}{ Co-morbidities } \\
\hline Hypertension & & $5(45.5 \%)$ \\
\hline COPD & & $3(27.3 \%)$ \\
\hline IHD & & $3(27.3 \%)$ \\
\hline \multicolumn{3}{|l|}{ Lab Values } \\
\hline Serum Ferritin & 1051.41(474-1668) & \\
\hline Ferritin $>362 \mathrm{ng} / \mathrm{ml}$ & & $11(100 \%)$ \\
\hline Serum LDH & $460.79(45-683)$ & \\
\hline \multicolumn{2}{|l|}{$L D H>220 u / L$} & $11(100 \%)$ \\
\hline D-Dimers & $1370.22(373-1725)$ & \\
\hline & $10(90.09 \%)$ \\
\hline $\begin{array}{l}\text { Lymphocyte count } \\
\text { Lymphocytes }<40 \%\end{array}$ & $11.80(05-68)$ & $10(90.09 \%)$ \\
\hline Neutrophils Ratio & $88.87(86-91)$ & \\
\hline \multicolumn{2}{|l|}{$\begin{array}{l}\text { Neutrophils > } 80 \% \\
\text { Tocilizumab }\end{array}$} & $11(100 \%)$ \\
\hline \multicolumn{3}{|l|}{ Cause of death } \\
\hline \multicolumn{2}{|l|}{ Cardiac Arrest } & $7(63.6 \%)$ \\
\hline \multicolumn{2}{|l|}{ Multiorgan dysfunction } & $2(18.2 \%)$ \\
\hline \multicolumn{2}{|l|}{ ARDS } & $2(18.2 \%)$ \\
\hline \multicolumn{3}{|c|}{$\begin{array}{l}\text { The table describes the characteristics and laboratory } \\
\text { results of all fatal cases included. In this study, } 63.6 \% \\
\text { of fatal cases were male and } 36.4 \% \text { were female, with } \\
\text { an average age of } 56.36 \text { years. The number of days of } \\
\text { patients remaining in hospital has been at most } 15 \\
\text { fatal cases have Co morbidities Hypertension. COPD } \\
\text { and HDD, but the hypertension rate was very high } \\
45.5 \% \text { were with hypertension and } 27.3 \% \text { were } \\
\text { combated cause was COPD and HDI. Another } \\
\text { important concern raised by this study was the high } \\
\text { readings of laboratory values we included in this case } \\
\text { some selected parameters of Covid- } 19 \text { patient's labs }\end{array}$} \\
\hline
\end{tabular}

[Cite: Rana MA, Qayyum A, Hashmi M, Saif MMU, Munir MF, Pervaiz R, Iqbal S, HAFEEZ MM. (2021). Mortality and COVID-19: A snapshot of a tertiary care facility in Pakistan. Pak. J. Inten. Care Med., 2021: 3. https://doi.org/10.54112/pjicm.v2021i1.3]. 


\section{Discussion}

The table describes the characteristics and laboratory results of all fatal cases included. In this study, $63.6 \%$ of fatal cases were male and $36.4 \%$ were female, with an average age of 56.36 years. The number of days of patients remaining in hospital has been at most 15 fatal cases have Co morbidities Hypertension. COPD and HDD, but the hypertension rate was very high $45.5 \%$ were with hypertension and $27.3 \%$ were combated cause was COPD and HDI. Another important concern raised by this study was the high readings of laboratory values we included in this case some selected parameters of Covid-19 patient's labs like serum ferritin, LDH, D-Dimers, Lymphocytes, and neutrophils. According to the results of this study, the average mean of serum Ferritin was 1051, minimum $=474$, maximum $=1668$ and these values were higher than the normal fruition in all patients. Similarly, the serum LDH mean value was 460.79 , minimum $=460$, maximum $=683$ these values were also higher in all cases. It was noted that in all fatal cases, serum ferritin and D dimer levels remained higher (average $=1051.41$ ) throughout treatment, while other markers were observed with a decreasing trend.

\section{Conclusion}

We can conclude from this study that the comorbid condition with Covid-19 infection has drastic outcomes and major cause of death in Bahira Town International Hospital, Lahore was acute coronary syndrome due to hypercoagulability. Furthermore, biochemical disturbance was also seen in all patients who were critically ill.

\section{Recommendations}

It is recommended, on the basis of above discussion, that the people with co morbid condition should take great care of themselves, and clinicians should deal with hypercoagulable state with great concern.

\section{Conflict of interest}

The authors declared no conflict of interest.

\section{Funding status}

This study is not funded by any third party.

\section{References}

Aggarwal, G., Cheruiyot, I., Aggarwal, S., Wong, J., Lippi, G., Lavie, C. J., Henry, B. M., and Sanchis-Gomar, F. (2020). Association of cardiovascular disease with coronavirus disease 2019 (COVID-19) severity: a metaanalysis. Current problems in cardiology, 100617.

Ali, J., Ali, Q., Hafeez, M., and Malik, A. (2020). Clinical features, diagnosis and treatment of COVID-19. Biol Clin Sci Res J 2020, e032.
Azkur, A. K., Akdis, M., Azkur, D., Sokolowska, M., van de Veen, W., Brüggen, M. C., O’Mahony, L., Gao, Y., Nadeau, K., and Akdis, C. A. (2020). Immune response to SARS-CoV-2 and mechanisms of immunopathological changes in COVID-19. Allergy 75, 1564-1581.

David, K. B., Thomas, N., and Solomon, J. K. (2020). Epidemiology of COVID-19 in Africa: daily cumulative index and mortality rate. International Journal of Infection Control 16, $1-5$.

Fu, Z., Tang, N., Chen, Y., Ma, L., Wei, Y., Lu, Y., Ye, K., Liu, H., Tang, F., and Huang, G. (2020). CT features of COVID-19 patients with two consecutive negative RT-PCR tests after treatment. Scientific Reports 10, 1-6.

Gietema, H. A., Zelis, N., Nobel, J. M., Lambriks, L. J., van Alphen, L. B., Oude Lashof, A. M., Wildberger, J. E., Nelissen, I. C., and Stassen, P. M. (2020). CT in relation to RT-PCR in diagnosing COVID-19 in The Netherlands: A prospective study. PloS one 15, e235844.

Lauretani, F., Ravazzoni, G., Roberti, M. F., Longobucco, Y., Adorni, E., Grossi, M., De Iorio, A., La Porta, U., Fazio, C., and Gallini, E. (2020). Assessment and treatment of older individuals with COVID-19 multi-system disease: clinical and ethical implications. Acta Bio Medica: Atenei Parmensis 91, 150.

Lima, C. K. T., de Medeiros Carvalho, P. M., Lima, I. d. A. A. S., de Oliveira Nunes, J. V. A., Saraiva, J. S., de Souza, R. I., da Silva, C. G. L., and Neto, M. L. R. (2020). The emotional impact of Coronavirus 2019-nCoV (new Coronavirus disease). Psychiatry research 287, 112915.

Mady, A., Ramdan, O., Al Yousef, R., Ishag, A., Bakirova, G., Kuhail, A., Shahzad, S., ElEtreby, W., Mumtaz, S., and Almozainy, S. (2020). COVID 19 critical care training surge experience for physicians in riyadh health cluster one, Saudi Arabia. Biological and Clinical Sciences Research Journal 2020, e041-e041.

Nadeem, U., Anjum, N., Farooq, F., and Gillani, S. (2021). A SONOGRAPHIC EVALUATION OF PEDIATRIC ACUTE ABDOMINAL PAIN: A SYSTEMATIC REVIEW. Biological and Clinical Sciences Research Journal 2021, e013-e013.

Nicola, M., O’Neill, N., Sohrabi, C., Khan, M., Agha, M., and Agha, R. (2020). Evidence based management guideline for the COVID-19

[Cite: Rana MA, Qayyum A, Hashmi M, Saif MMU, Munir MF, Pervaiz R, Iqbal S, HAFEEZ MM. (2021). Mortality and COVID-19: A snapshot of a tertiary care facility in Pakistan. Pak. J. Inten. Care Med., 2021: 3. https://doi.org/10.54112/pjicm.v2021i1.3]. 
pandemic-Review article. International Journal of Surgery.

Seah, I., and Agrawal, R. (2020). Can the coronavirus disease 2019 (COVID-19) affect the eyes? A review of coronaviruses and ocular implications in humans and animals. Ocular immunology and inflammation 28, 391-395.

Siddique, A., Fateh, A., Idrees, N., Ali, Q., Hafeez, M., and Malik, A. (2020). The epidemics of COVID-19. Biological and Clinical Sciences Research Journal 2020, e030-e030.

Tabassum, S., Bibi, T., Tariq, F., TARIQ, S., RAZA, S., HAFEEZ, M., and RANA, M. (2020). UNUSUAL LEUKEMOID REACTION IN A COVID-19 PATIENT: A CASE REPORT Biol Clin Sci Res J 8, 16PM.

Tu, W.-J., Cao, J., Yu, L., Hu, X., and Liu, Q. (2020). Clinicolaboratory study of 25 fatal cases of COVID-19 in Wuhan. Intensive care medicine 46, 1117-1120.

Wu, J., Shen, J., Han, Y., Qiao, Q., Dai, W., He, B., Pang, R., Zhao, J., Luo, T., and Guo, Y. (2021). Upregulated IL-6 Indicates a Poor COVID-19 Prognosis: A Call for Tocilizumab and Convalescent Plasma Treatment. Frontiers in immunology 12, 455.

Zheng, F., Tang, W., Li, H., Huang, Y., Xie, Y., and Zhou, Z. (2020a). Clinical characteristics of 161 cases of corona virus disease 2019 (COVID-19) in Changsha. European Review for Medical and Pharmacological Sciences 24, 3404-3410.

Zheng, T., Yang, C., Wang, H. Y., Chen, X., Yu, L., Wu, Z. L., and Sun, H. (2020b). Clinical characteristics and outcomes of COVID-19 patients with gastrointestinal symptoms admitted to Jianghan Fangcang Shelter Hospital in Wuhan, China. Journal of medical virology 92, 2735-2741.

Zhu, Y., Gao, Z.-H., Liu, Y.-L., Xu, D.-Y., Guan, T.M., Li, Z.-P., Kuang, J.-Y., Li, X.-M., Yang, Y.-Y., and Feng, S.-T. (2020a). Clinical and CT imaging features of 2019 novel coronavirus disease (COVID-19). Journal of Infection 81, 147-178.

Zhu, Y., Xie, J., Huang, F., and Cao, L. (2020b). The mediating effect of air quality on the association between human mobility and COVID-19 infection in China. Environmental research 189, 109911.

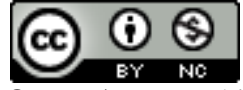

Open Access This article is licensed under a Creative Commons Attribution 4.0 International License, which permits use, sharing, adaptation, distribution and reproduction in any medium or format, as long as you give appropriate credit to the original author(s) and the source, provide a link to the Creative Commons licence, and indicate if changes were made. The images or other third party material in this article are included in the article's Creative Commons licence, unless indicated otherwise in a credit line to the material. If material is not included in the article's Creative Commons licence and your intended use is not permitted by statutory regulation or exceeds the permitted use, you will need to obtain permission directly from the copyright holder. To view a copy of this licence, visit http://creativecommons.org/licen ses/by/4.0/.

(C) The Author(s) 2021

[Cite: Rana MA, Qayyum A, Hashmi M, Saif MMU, Munir MF, Pervaiz R, Iqbal S, HAFEEZ MM. (2021). Mortality and COVID-19: A snapshot of a tertiary care facility in Pakistan. Pak. J. Inten. Care Med., $2021: 3$. https://doi.org/10.54112/pjicm.v2021i1.3]. 